\title{
Quality of Affined Sugar at Different Temperatures
}

Samy El-Syiad ${ }^{\text {a) }}$, Abdel-Aal M. Gaber ${ }^{b)}$, Sayed Z. Osman ${ }^{c)}$ and Waleed R. Abd Al-Fattah ${ }^{c}$

a) Food Science and Technology Department, Faculty of Agriculture, Assiut University, Egypt.

${ }^{b)}$ Faculty of Sugar and Integrated Industries Technology and Chemistry

Department, Faculty of Science, Assiut University, Egypt.

${ }^{c}$ Hawamidiya refinery factory, Egyptian Sugar and Integrated Industries Company, Gize, Egypt.

\begin{abstract}
The study is done to evaluate the quality of the sugar produced from the affination processes after applying different temperature $60{ }^{\circ} \mathrm{C}, 70^{\circ} \mathrm{C}$ and $80^{\circ} \mathrm{C}$, and study the chemical and physical properties of affined sugar .From the results it is clear that the appropriate temperature at $70^{\circ} \mathrm{C}$. Atthis temperature, it gives highest de colorization and polarization, less in polysaccharides content (dextran), reducing sugar and ash ratio.
\end{abstract}

Keywords: Raw sugar, Affination, Temperature, Dextran, Decolorization.

\section{Introduction}

Raw sugar crystal is covered with a film of molasses containing impurities and coloring matter, the average purity of this film is about $70 \%$, the film can be removed very easily by affination $^{(1)}$. Affination processes means that treatment of raw sugar crystals with a concentrated syrup to remove the film of adhering molasses, this is achieving by mixing sugar with syrup and then centrifuging the magma with or without water washing (2). Generally, there is a relationship between the quality of raw sugar and the difficulties in turning it into good quality white sugar ${ }^{(3)}$. There are some factors affectingon the efficiency and effectiveness of the affination process such as:

Crystal grain size, moisturecontent andimpurities in rawsugar ${ }^{(4)}$.

In this paper, the effect of the temperature on the affination process and the quality of affined sugar has been studied. In sugar 
refineries, the temperature of the magma may be varied according to the raw sugar impurities ranged from $60^{\circ} \mathrm{C}$ to $75^{\circ} \mathrm{C}{ }^{(2)}$.

\section{Materials and methods.}

\subsection{Materials.}

Accumulating representative samples of raw sugar supplied from Brazil to the Hawamidiya refinery sugar factory, the samples were collected to representative 100,000-ton raw sugar. A number of ten samples were collected to study the chemical and physical properties, and there was convergence in all properties except for the dextran ratio in sample number five and nine, so the study was done on them.

\subsection{Methods.}

\subsubsection{Analytical methods.}

Polarization, reducing sugar, ash, moisture, starch and color determine according to ICUMSA (2017) methods ${ }^{(5)}$.

Safety factor, which are related to the moisture content of raw sugar, serve as quality criteria for raw sugar storage ${ }^{(2)}$. The safety factor found by Whalley ${ }^{(6)}$ is defined as

$$
\mathrm{SF}=\frac{\text { moisture }(\%)}{100-\text { polarization }}
$$

\subsubsection{Roberts method for determination dextran}

This method can be used for raw sugar and refined sugar, can juice, syrups, and molasses. It is a quantitative method for total dextran, in which all of the polysaccharides are separated from the sugar by precipitation with $80 \%$ ethanol, and dextran is selectively precipitated from the polysaccharides mixture with alkaline copper sulfate. The dextran in the precipitate is then determined calorimetrically ${ }^{((7)}$. A device was used spectrophotometer jenway model 6300.

Preparation of standard curve by using standard dextran Mr- 70000, dextran from leuconostoc spp. 
The dextran is precipitated from 40 gram of raw sugar, and applying the steps of the Robert method ${ }^{(7)}$. Moreover, applying this equation to can be estimated the dextran in sugar samples.

$$
\text { ppm }=\mathrm{F} \times \mathrm{E} \times \frac{C}{D} \times \frac{1}{B} \times \frac{100}{A} \times \mathbf{1 0 0 0}
$$

Where $A=$ wt of sample solid diluted to $100 \mathrm{ml}$

$\mathrm{B}=$ aliquot taken for alcohol precipitation $(\mathrm{ml})$

$\mathrm{C}=\mathrm{ml}$ of solution of alcohol precipitate

$\mathrm{D}=$ aliquot taken for copper precipitation $(\mathrm{ml})$

$\mathrm{E}=\mathrm{ml}$ of final solution of copper -dextran complex

$\mathrm{F}=\mathrm{mg} / \mathrm{kg}$ dextran (from standard curve)

\subsubsection{Affinaion methods}

This method is applicable to all raw sugar toremove the film of molasses coating of sugar crystal.

Sugar solution (saturated)

Add $300 \mathrm{~g}$ distilled water to $700 \mathrm{~g}$ refined sugar in a $2 \mathrm{~L}$ beaker. Stir at room temperature until no further sugar dissolves (approximately 12 hours). Check that the solution is saturated by measuring the Brix (the sucrose saturation point at $20^{\circ} \mathrm{C}$ is \pm $66.6^{\circ} \mathrm{Bx}$ ). Filter the syrup through coarse calico or other cloth to obtain approximately $850 \mathrm{~cm} 3$ of syrup $^{(8)}$. The solution is then heated in water bath to the desired temperature $60^{\circ} \mathrm{C}, 70^{\circ} \mathrm{C}$ and $80^{\circ} \mathrm{C}$,will be added the solution to the samples with heating to keep the heat and stirring simples without dissolving the crystals.

Weigh $1200 \pm 10 \mathrm{~g}$ raw sugar into wide-mouthed container. Add $1000 \mathrm{~cm}^{3}$ of the saturated sugar solution, using the measuring cylinder. Screw the lid on tightly and tumble at $20 \mathrm{rpm}$ for 30 minutes. Pour the magma in a steady stream into the centrifuge basket spinning at $500-1000 \mathrm{rpm}$.

Wash the sugar with $50 \mathrm{~cm}^{3}$ cold distilled water using a wash bottle with a fine jet. Increase the speed to $3500 \pm 200 \mathrm{rpm}$ and spin for 6 minutes. stop the centrifuge and remove the basket ${ }^{(8)}$.

The sugar yield from centrifuge was dried, and determined all physical and chemical properties. 
3. Result and Discussion

Table 1. Analysis sample of raw sugar

\begin{tabular}{|c|c|c|c|c|c|c|c|c|c|}
\hline Sample & Moist \% & $\begin{array}{c}\text { Safety } \\
\text { factor }\end{array}$ & $\begin{array}{c}\text { Polarization } \\
(\mathbf{Z})\end{array}$ & $\begin{array}{c}\text { Starch } \\
(\mathbf{p p m})\end{array}$ & $\begin{array}{c}\text { Dextran } \\
(\mathbf{p p m})\end{array}$ & $\begin{array}{c}\text { Reducing } \\
\text { sugar \% }\end{array}$ & $\begin{array}{c}\text { Ash \% } \\
\text { gm }\end{array}$ & $\begin{array}{c}\text { Reducing sugar } \\
\text { /ratio ash }\end{array}$ & $\begin{array}{c}\text { Color } \\
\text { (IU) }\end{array}$ \\
\hline 1 & 0.07 & 0.13 & 99.45 & 386 & 485 & 0.14 & 0.11 & 1.3 & 670 \\
2 & 0.07 & 0.11 & 99.36 & 370 & 350 & 0.15 & 0.11 & 1.4 & 662 \\
4 & 0.08 & 0.13 & 99.38 & 385 & 425 & 0.17 & 0.12 & 1.4 & 653 \\
5 & 0.06 & 0.09 & 99.35 & 400 & 323 & 0.16 & 0.11 & 1.5 & 655 \\
6 & 0.06 & 0.11 & 99.45 & 385 & 525 & 0.16 & 0.12 & 1.3 & 675 \\
7 & 0.07 & 0.11 & 99.35 & 401 & 343 & 0.16 & 0.11 & 1.5 & 660 \\
8 & 0.07 & 0.11 & 99.35 & 375 & 362 & 0.17 & 0.11 & 1.5 & 710 \\
9 & 0.06 & 0.11 & 99.45 & 385 & 548 & 0.15 & 0.12 & 1.3 & 690 \\
10 & 0.07 & 0.10 & 99.28 & 410 & 325 & 0.14 & 0.12 & 1.2 & 660 \\
\hline
\end{tabular}




\section{Table1illustrates the following items:}

\section{Moisture}

The moisture of raw sugar is probably the most important parameter determining its stability and keeping quality during storage ${ }^{(9)}$. Destruction of sugar by osmophilic yeasts could take place in the syrup film surrounding the crystal providing conditions that are appropriate and sufficiently diluted ${ }^{(3)}$. The relation shape between moisture and non-sucrose in raw sugar expressed in terms of "the safety factor"

\section{Polarization}

Polarization of raw sugar ranged from 99.25 to 99.45 . Polarization is an important parameter in raw sugar. The higher polarization of raw sugar mean lower the impurity load on the refinery, and the higher the refined sugar output or yield per ton ${ }^{(9)}$. Generally, in raw sugar payment systems one of the primaries is polarization.

\section{Starch}

The samples contain high starch content, starch occurs naturally in cane as smell granules, it can be easily removed by filtering, when the largest granules readily gelatinized and increase viscosity. About $30 \%$ of the starch in juice eventually appears in raw sugar crystal ${ }^{(9)}$. In the carbonation refining process, it interferes with the precipitation and coagulation of calcium carbonate crystals. This results in poor filterability after clarification ${ }^{(11)}$.It is generally accepted that starch level exceeding 250ppm raw sugar cause refinery problem ${ }^{(9)}$. In these samples from the sugar-refining factory in Hwamadia, Egypt, starch analyzes are higher than250ppm, which lead to a problem in refining processes.

\section{Color}

The results showed that color value ranged from 650 to 710 IU, and the results are considered convergent. The color in raw sugar plays an important role in sugar refinery ${ }^{(12)}$.color removal is the basic principle of sugar refining and the proportion and nature of the colorants in the raw sugar that can determine the cost of refining. 


\section{Dextran}

Dextran Content ranged from 323 to 548 ppm, dextrancauses many problems in sugar refining which cause slow the rate of filtration of refined liquors and reducing factor capacity ${ }^{(2)}$.Dextran in final refined sugar also causes problems for the producers of sugar containing products, especially hard candies and cordial liquors $^{(10)}$.

\section{Ash}

Affination is the main ash remove process, in the carbonation process and de colorization by bone char can remove a small amount do residual ash in affination process ${ }^{(11)}$. The ratio of ash in samples ranged between 0.11 to $0.12 \% \mathrm{gm}$, some authors have specified $1000 \mathrm{mg} / \mathrm{kg}$ as the maximum level for ash in affinated sugar, and other quotes a lower ratio from 300 to $400 \mathrm{mg} / \mathrm{kg}^{(9)}$.

Table 1 illustrates that the safety factor ranged from (0.09 to 0.13$)$ in which the safe limit is $0.25^{(2)}$, therefore all samples less than limit, and thus the sugar could be stored without danger.

Table 2. Affination process at temperature $\left(60^{\circ} \mathrm{C}\right)$

\begin{tabular}{|l|l|l|l|l|}
\hline Content of sugar & \multicolumn{2}{|c|}{ Sample 5 } & \multicolumn{2}{c|}{ Sample 9 } \\
\cline { 2 - 5 } & $\begin{array}{l}\text { Raw } \\
\text { sugar }\end{array}$ & $\begin{array}{l}\text { Affined } \\
\text { sugar }\end{array}$ & $\begin{array}{l}\text { Raw } \\
\text { sugar }\end{array}$ & $\begin{array}{l}\text { Affined } \\
\text { sugar }\end{array}$ \\
\hline \hline Polarization Z & 99.45 & 99.55 & 99.45 & 99.50 \\
Dextran ppm & 525 & 380 & 548 & 392 \\
Starch ppm & 385 & 380 & 392 & 385 \\
Ash \%gm & 0.12 & 0.03 & 0.11 & 0.04 \\
Reducing sugar\%gm & 0.16 & 0.09 & 0.14 & 0.07 \\
Color IU & 675 & 588 & 690 & 600 \\
\hline
\end{tabular}

Table 2 shows that the affination process at temperature $60^{\circ} \mathrm{C}$, increases the polarization by 0.05 to 0.1 , and higher polarization leads to an improvement in sugar quality and an increase in refining output. 
Decreased the ratio of ash, reducing sugar and color but starch is still almost unchanged. Dextran decreased by up to $27 \%$.

Table 3. Affination process at temperature $70^{\circ} \mathrm{C}$

\begin{tabular}{|l|l|l|l|l|}
\hline \multirow{2}{*}{ Content of sugar } & \multicolumn{2}{|c|}{ Sample 5 } & \multicolumn{2}{c|}{ Sample 9 } \\
\cline { 2 - 5 } & $\begin{array}{l}\text { Raw } \\
\text { sugar }\end{array}$ & $\begin{array}{l}\text { Affined } \\
\text { sugar }\end{array}$ & $\begin{array}{l}\text { Raw } \\
\text { sugar }\end{array}$ & $\begin{array}{l}\text { Affined } \\
\text { sugar }\end{array}$ \\
\hline Polarization $\mathbf{Z}^{\mathbf{0}}$ & 99.45 & 99.62 & 99.45 & 99.62 \\
Dextran ppm & 525 & 233 & 548 & 252 \\
Starch ppm & 385 & 382 & 392 & 385 \\
Ash \%gm & 0.12 & 0.02 & 0.11 & 0.02 \\
Reducing sugar \% gm & 0.16 & 0.09 & 0.14 & 0.07 \\
Color IU & 675 & 475 & 690 & 490 \\
\hline
\end{tabular}

Table 3 show that the affinationt at temperature $70{ }^{\circ} \mathrm{C}$, the ratio of dextran decrease by $50 \%$, the quality of affined sugar increase in terms of ash content and reducing sugar

The polarization increased at temperature $70^{\circ} \mathrm{C}$ about temperature $60{ }^{\circ} \mathrm{C}$.

Table 4. Affination process at temperature $80^{\circ} \mathrm{c}$

\begin{tabular}{|l|c|c|c|c|}
\hline \multirow{2}{*}{ Content of sugar } & \multicolumn{2}{|c|}{ Sample 5 } & \multicolumn{2}{c|}{ Sample 9 } \\
\cline { 2 - 5 } & $\begin{array}{c}\text { Raw } \\
\text { Sugar }\end{array}$ & $\begin{array}{c}\text { Affined } \\
\text { sugar }\end{array}$ & $\begin{array}{c}\text { Raw } \\
\text { sugar }\end{array}$ & $\begin{array}{c}\text { Affined } \\
\text { sugar }\end{array}$ \\
\hline Polarization Z & 99.45 & 99.55 & 99.45 & 99.60 \\
Dextran ppm & 525 & 328 & 548 & 352 \\
Starch ppm & 385 & 380 & 392 & 385 \\
Ash \%gm & 0.12 & 0.03 & 0.11 & 0.04 \\
Reducing sugar \%gm & 0.16 & 0.09 & 0.14 & 0.07 \\
Color IU & 675 & 518 & 690 & 533 \\
\hline
\end{tabular}


Table 4 show that the affination at temperature $80^{\circ} \mathrm{C}$, in this temperature dextran decreased by $27 \%$, it is less than the ratio at temperature $70^{\circ} \mathrm{C}$ and de colorization is less, the low ratio of ash and reducing sugar is almost close to the different temperature.

Table 5. decolorization $\%$ at different temperature.

\begin{tabular}{|c|c|c|c|}
\hline $\begin{array}{c}\text { No of } \\
\text { sample }\end{array}$ & $\begin{array}{c}\text { de colorization at } \\
\mathbf{T}(60) \cdot \mathbf{C} \%\end{array}$ & $\begin{array}{c}\text { de colorization } \\
\text { at }(\mathbf{7 0}) \circ \mathbf{c} \%\end{array}$ & $\begin{array}{c}\text { de colorization at T }(\mathbf{8 0}) \circ \\
\mathbf{C} \%\end{array}$ \\
\hline 5 & 13 & 30 & 23 \\
9 & 13 & 29 & 23 \\
\hline
\end{tabular}

Table 5 shows that the following percentage of de colorization at the different temperature of the affination process, the de colorization at $70^{\circ} \mathrm{C}$ above than at temperature $60,80^{\circ} \mathrm{C}$. From the results obtained that the appropriate temperature for the affination process at temperature $70^{\circ} \mathrm{C}$, at temperature $70^{\circ} \mathrm{C}$ highest de colorization and polarization and lowest dextran content, ash and reducing sugar.

\section{Conclusion}

The aim of the present work is to study the effect of temperature on the quality of affined sugar. The results clear that the optimum temperature of affination is $70^{\circ} \mathrm{C}$, at this temperature gives affined sugar is high in polarization, highly decolorizing and has lower dextran, ash and reducing sugar content. At temperature $80^{\circ} \mathrm{C}$ and $60^{\circ} \mathrm{C}$ the results are not good with compared temperature $70^{\circ} \mathrm{C}$.

\section{Reference}

1. V.E. BIKW (1982), manufacture and refining of raw cane sugar, Elsevier scientific publishing company; Amsterdamoxford-New York. Scand addition; 303,304.

2. Chung - chi-chou (2000), Handbook of sugar refining; sugar process research institute, New Orleans-Louisiana.; P3, 38,517 .

3. Waston. A. J \&Wilson. N.M (1975), Sugar technology reviews, Elsevier publishing company; Amsterdam. . 
4. James, C.P.C, \&Honing (1965), p. Ash content of Peruvian raw sugar. Sugar Journal, October. P 42-47.

5. ICUMSA (2017). International Commission for Uniform Method of Sugar Analysis.

6. T. G. Whalley (1954), proc. Queensl . Soc. Sugar Cane Technol, p 27-39.

7. Anon (1990), Dextran in raw cane sugar. Roberts copper method, Official Methods of Analysis of the Association of Official chemists. Arlington, USA $15^{\text {th }} \mathrm{Ed} ., 988$.

8. SASTA (2005). Laboratory Manual for South African Sugar Factories. 5thEdition: Section 7.1.

9. Beter Rein (2017), Cane sugar Engineering, Verlag Dr. Albert Bartens KG - Berlin 2d.p 491.

10. G. W. Vane (1981), Sugar Ind. Techanol. 40:95-102.

11. Donovan M. (1993), Raw sugar quality. The effect on the refinerproc. Sugar Ind. Technol. 52,117-130.

12. Spencer, G.L., \& Meade.G. P (1959). Cane sugar handbook $\left(8^{\text {th }}\right.$ ed). New York: John Wiley and Sons.

13. P. W van der Pol, H. Schiweck, T. Schwartz (1998). Sugar Technology Beet and Cane Sugar Manufacture, Beet Sugar Development Foundation, Denver, USA. 


\section{الملغض العربي}

جودة السكر المغسول هبدئيا (Affination process) عند دراجات حرارة هختلفة

ساهي الصياد1 ، عبد العال همهد جابر² ، سيد ذكي عثهان 33 ، وليد رهضان عبد الفتاح 3

1 قسم علوم الأغذبية- كلية الززراعة - جاهعة اسيوط

$2{ }^{2}$

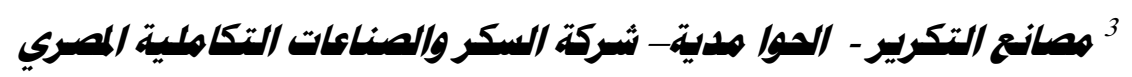

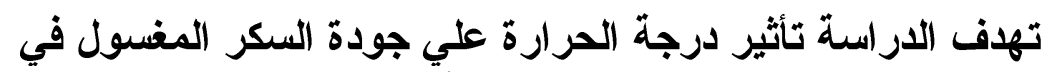

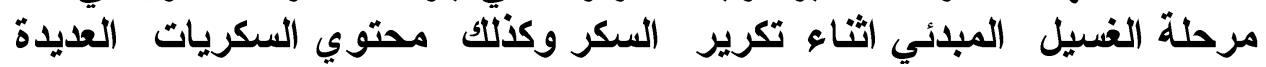

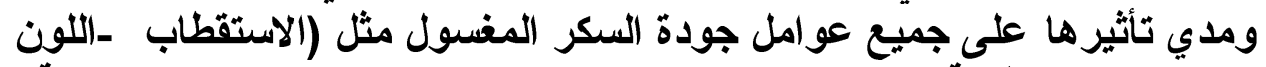

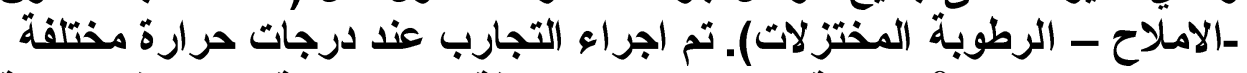

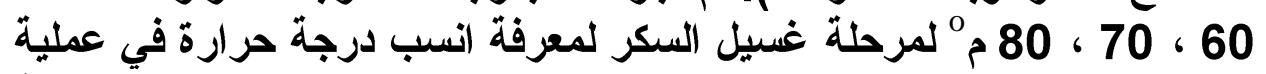

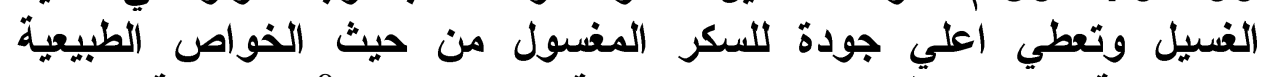

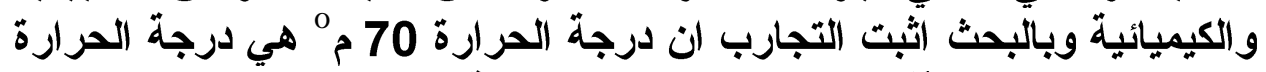

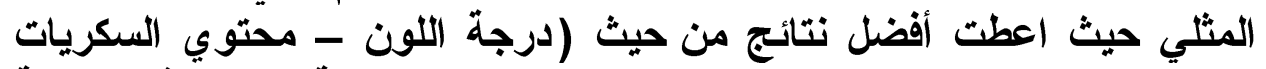

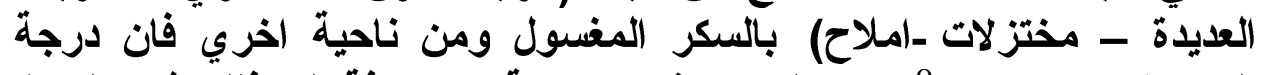

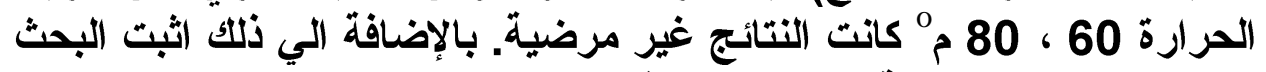

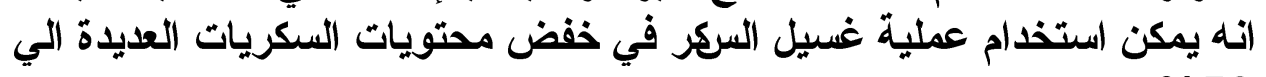

.\%50

运然 